\title{
THE ANALYSIS AND RESEARCH FOR THE PLATE DIFFERENTIAL OXYGEN GAS SENSOR OF AUTO BASED ON THE TEMPERATURE FIELD AND THERMAL STRESS FIELD
}

\author{
JianjunYANG \\ School of Automobile, Wuhan University of Technology, Wuhan 430070, China , \\ School of Automobile, Wuhan Business University, Wuhan 430056,China \\ E-mail: yangjianjun1101@yeah.net
}

\begin{abstract}
The purpose of this paper is to study the oxygen field sensor based on the temperature field and the thermal field. By using cerium - zirconium oxygen storage material as the oxygen partial pressure reference layer, the multi - layer structure of flat - type concentration oxygen sensor was designed. The finite element model of the sensor is established. Thermal conductivity and thermal stress analysis of 8YSZ and 3YSZ different electrolyte sensors were carried out respectively. The results show that the sensor reaches the response temperature above $300{ }^{\circ} \mathrm{C}$ at $\mathrm{t}$ $=5 \mathrm{~s}$. When the sensor is stable, the temperature of the sensitive area is about $800{ }^{\circ} \mathrm{C}$. At the same time, it shows consistency in the thickness direction. The thermal stress of each layer of the sensor increases with increasing temperature. When the sensor is stable, it reaches its maximum value. However, they are less than the breaking strength of each material. Based on the above findings, we conclude that the plate type concentration oxygen sensor based on temperature field and thermal field has the advantages of fast response time and reliable performance.
\end{abstract}

Keywords: temperature field, thermal stress field, flat type, concentration type, automotive oxygen gas sensor.

\section{Introduction}

Since the exhaust gas sensor is made of zirconia electrolyte, the sensor has to meet the temperature of the electrolyte to start the work [5]. General exhaust gas is not sufficient for the sensor to reach this temperature [7]. In the traditional tubular oxygen sensors, an independent ceramic heater is introduced, which greatly shortens the time required for the response [6]. However, it is still unable to meet the exhaust emission vehicle (SULEV) response time requirements [9]. As a result, we need an oxygen sensor that heats up more quickly [8]. These requirements have accelerated the development of the flat structure of the sensor to the integrated heater [10]. The panel type oxygen sensor has the advantages of fast response, low energy consumption and good performance [13]. However, as it integrates the heater, the sensor will suffer greater thermal gradients and thermal stresses [12].

By employing partially stabilized zirconia (PSZ) as a solid electrolyte, a reasonable design can satisfy the requirements of the sensor's operating temperature, response time and intensity [11]. However, the thermal analysis of fully stabilized zirconia (FSZ) as an oxygen sensor electrolyte is relatively small. This is mainly due to the poor mechanical properties of FSZ [14].

In addition, according to the Nernst principle, the flat-type concentration oxygen sensor must have an air channel to provide a constant reference oxygen partial pressure, which makes its structure and manufacturing process complex [15]. This is not easy to miniaturization. The use of oxygen storage materials as a solid gas reference layer gives a new way to solve this problem [18].

However, this material does not match the thermal expansion coefficient of the electrolyte material, which may cause the sensor to suffer from greater thermal stress and break [17]. Therefore, it is necessary to start from the structure and materials, looking for the use of the requirements of the oxygen sensor.

At present, there are mainly two effective measures to reduce and control automobile exhaust emissions. One is an EFI engine three element catalytic control system, and the other is an EFI engine lean combustion system [16]. The ternary catalytic control system is equipped with an exhaust gas transfer device on the exhaust pipe [19]. By using platinum, rhodium and palladium as a catalyst, it converts the harmful gases in the off-gas into nonaerobic nitrogen, water, carbon dioxide and so on. 
This method was first applied in 1977 by the German company BOSCH VOLVO type internal combustion engine [20]. Subsequently, it was used to control vehicle exhaust emissions, which is currently the world's most effective measures to control vehicle exhaust emissions. With the economic growth, the automobile industry has developed rapidly. According to statistics, in 2013, China's car ownership was 125 million vehicles. By 2014, it reached 154 million vehicles, and by May 2015, it had more than 162 million vehicles [21]. Since 2010, the average annual growth rate of car ownership in the country has exceeded 15\% [1-3].A large number of cars provide convenience for people's life. At the same time, it also brings many negative effects, such as traffic accidents, energy consumption, exhaust gas and noise pollution. Among them, the exhaust gas emitted by automobiles is a major air pollution source in the world, which seriously affects the ecological environment and people's physical and mental health [4].At present, the electronic injection system has replaced the traditional carburetor as the fuel supply mode of the automobile engine. Among them, the automobile oxygen sensor is the detection element in the closed-loop control system of EFI engine [26]. It is one of the key components to improve the combustion efficiency of automobile engines, control the exhaust emissions of automobiles and reduce the environmental pollution caused by automobiles [27].According to statistics, most of the automotive oxygen sensor design life is 60 thousand $\mathrm{km}$ [28]. Some sensors live up to 100 thousand kilometers. According to the average life span of 80 thousand kilometers, if a car runs 40 thousand kilometers per year, for about 2 years, it will need to replace the new oxygen sensors [29].According to environmental protection requirements, oxygen sensors must be installed in the newly manufactured gasoline vehicles [23].Some of the models in the three way catalytic converter (TWC) before and after each equipped with an oxygen sensor, which uses hydrogen peroxide sensor [30].According to the current domestic car ownership base and the number of new cars every year, it is estimated that 100 million oxygen sensors are needed per year [24].Although there are hundreds of manufacturers of oxygen sensors in China, the quality of the sensors produced is not up to the advanced level in other countries [25].At present, Germany BOSCH, the United States DELPHI, Japan DEOSO and Japan NGK occupy the sensor market [22].

In summary, the oxygen sensor product performance and emissions regulations, large sensor market increasingly stringent and backward technology makes the development of China's independent property and high reliability is particularly urgent and important. In this paper, the finite element model of the sensor is established by using the cerium-zirconium oxygen storage material as the solid oxygen storage reference layer. The temperature field and thermal stress field of the sensor are established. The effects of 8YSZ and 3YSZ electrolyte on the thermal stress of the sensor were simulated and compared.

\section{State of the art}

Heat transfer is a science that studies the heat transfer, which expresses the law of conservation of nature in the form of heat. For a closed system, it can be described as:

$$
\mathrm{Q}-\mathrm{W}=\Delta \mathrm{U}+\Delta K_{E}+\Delta P_{E}
$$

In the formula, $\mathrm{Q}$ is the heat, $\mathrm{W}$ is the work, $\Delta \mathrm{U}$ is internal energy of system, $\Delta K_{E}$ is system function, $\Delta P_{E}$ is potential energy of system. For most of the project heat transfer problem, there is $\Delta K_{E}=\Delta P_{E}=0$ without considering the work $(\mathrm{W}=0)$, then $\mathrm{Q}=\Delta \mathrm{U}$.

There are three basic ways of heat transfer such as heat conduction, thermal convection and heat radiation. Heat conduction refers to the heat exchange behavior between two objects that are in contact with each other or between different parts of the same object due to the difference in temperature. Heat conduction follows the Fourier law:

$$
\mathrm{q}^{v \prime}=-\mathrm{k} \frac{d T}{d x}
$$

In the formula, q" is the density of heat flux and $\mathrm{k}$ is the thermal conductivity. The negative sign indicates that the heat is transferred in the direction of low temperature.

Thermal convection refers to the heat exchange behavior between the solid surface and its surrounding fluid due to differences in temperature. The thermal convection process can be described by the Newton cooling equation:

$$
\mathrm{q}^{n}=\mathrm{h}\left(T_{S}-T_{B}\right)
$$

In the formula, $\mathrm{h}$ is the convective heat transfer coefficient, $T_{S}$ is the solid surface temperature and $T_{B}$ is the ambient fluid temperature.

When the temperature of the various parts of the body has changed, the various parts will form linear strain $\alpha_{T}\left(\phi_{T}-\phi_{O}\right)$ due to deformation, where $\alpha_{T}$ is the coefficient of linear expansion of the material. $\phi_{T}$ is a point in the instantaneous temperature of the object), and $\phi_{O}$ is the initial temperature of the point. If the object's thermal deformation is not bound, the deformation of the object will not produce stress. However, when the object is constrained or the temperature of each part 
is not uniform, and the thermal deformation cannot be carried out freely, then the stress will be produced in the object. At present, there are few theoretical studies on the stress analysis of ceramic materials. The elastoplastic finite element theory is mainly used. There is a generalized stress $\sigma$, when $\sigma$ reaches to a limit value of yield, the ceramic material will be damaged.

For thermal stress analysis, ANSYS provides three kinds of methods: One is the direct method, which means the direct definition of node temperature (if the temperature of all nodes is known). Node temperature is used for thermal stress analysis.
The second is the indirect disaster legal, which means to get the temperature data of each node through thermal analysis, and then take the node temperature as the thermal stress analysis of the body load. The third is the direct legal trouble, which means to use the coupling unit with two freedom degrees of temperature and displacement.

The effects of thermal analysis on thermal stress analysis are considered in this study, and take no account of the opposite influence of thermal stress analysis on thermal analysis. This process is called unidirectional coupling. Therefore, the indirect method is used to calculate the thermal stress field. Fig. 1 is a data flow diagram using indirect hazards.

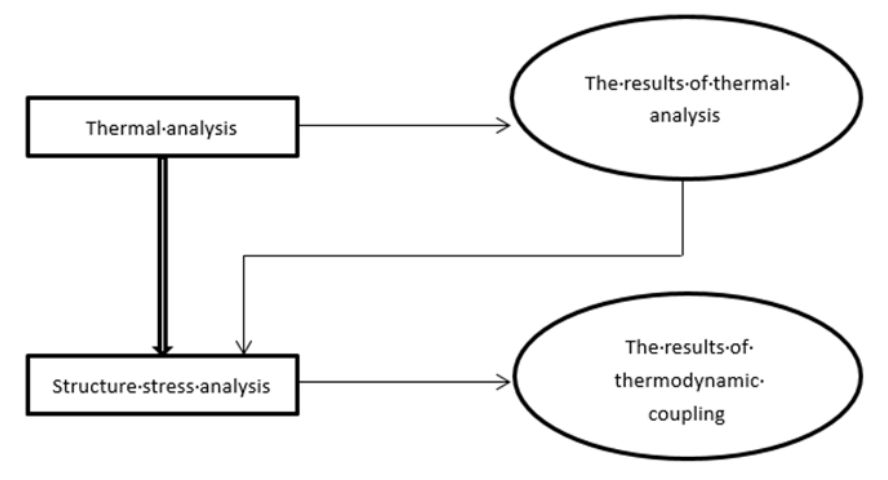

Figure 1: The flow chart of indirect coupling analysis

\section{Methodology}

\subsection{Structure analysis}

The plate type oxygen sensor is generally a multilayer structure, which includes a conductive pin, a substrate, an insulating layer, a heater, a reference air channel, an internal and external electrode, a solid electrolyte, and a porous protective layer.

The heater layer of oxygen sensor is usually made of precious metal platinum. Generally, it is made in thin structure in order to save costs. The heating region should focus on the front in order to ensure the efficiency of heating. Usually, the resistance in front of heater accounts for more than $80 \%$ of the total resistance heater. In order to ensure uniform heating, the front end is designed to the winding with uniform width.
The size of the schematic is shown in Fig. 2, and the unit is $\mathrm{mm}$. The inner and outer electrodes of the oxygen sensor are usually coated with a printing process on a solid electrolyte, and then sintered into a whole. The thickness of the oxygen sensor is relatively small. Because of its good insulation performance and the similar expansion coefficient to that of the upper and lower layers, alumina is selected as the insulating layer and the substrate layer. In order to simplify the model, the insulation layer of the material and the substrate layer are combined with the substrate to form a layer. Because the area is far away from the heater winding $(>10 \mathrm{~mm})$ part of the sensor temperature and thermal stress is low, the modeling length is selected as $22 \mathrm{~mm}$ instead of $60 \mathrm{~mm}$. The size of several parts needed to be modeled is shown in Fig. 3, and the unit is $\mathrm{mm}$.

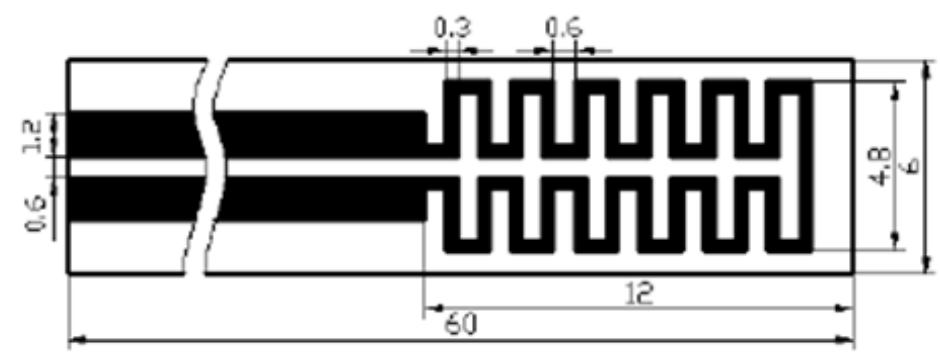

Figure 2: The structure diagram of the heater 


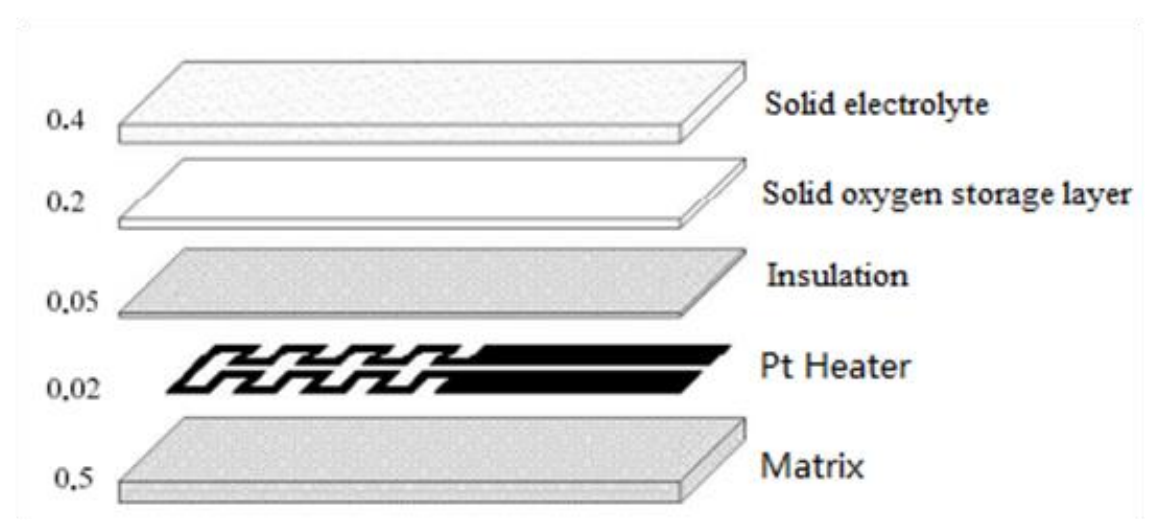

Figure 3: The dimension part to be built

\subsection{Mesh partition}

Three dimensional thermal analysis unit SOLID69 is used in the heat conduction analysis. The unit has 8 nodes, and each node has two degrees of freedom of temperature and voltage. The results of thermal field analysis are carried out, and the corresponding structural analysis unit SOLID45 is adopted. Each node of the element has 3 degrees of freedom along the XYZ direction. The bottom-up modeling method is used to model each layer, and then glue them together. According to the geometric characteristics of the model, the grid partition is adopted. The heater is divided into two parts because of the small size of the heater.

\section{Result analysis and discussion}

\subsection{Electrothermal coupling analysis}

The response speed of sensor and the temperature when it is stability all satisfy the needs by applying the step voltage to and stability. The specific method is: A high voltage is applied at the beginning stage to make the sensor reaching the response temperature with rapid speech. Meanwhile, the voltage value is gradually reduced until the sensor stable at working temperature. The optimization process of step voltage is shown in Fig. 4. The relationship between the voltage and time obtained by heat conduction analysis are shown in Fig. 5.

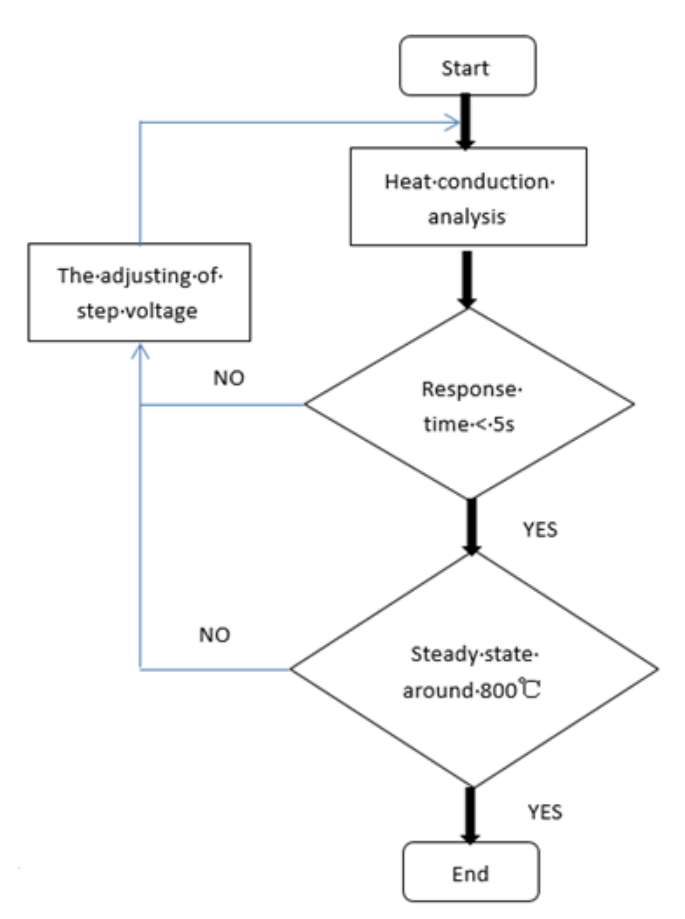

Figure 4: The Optimization Design Flow of Step Voltage 


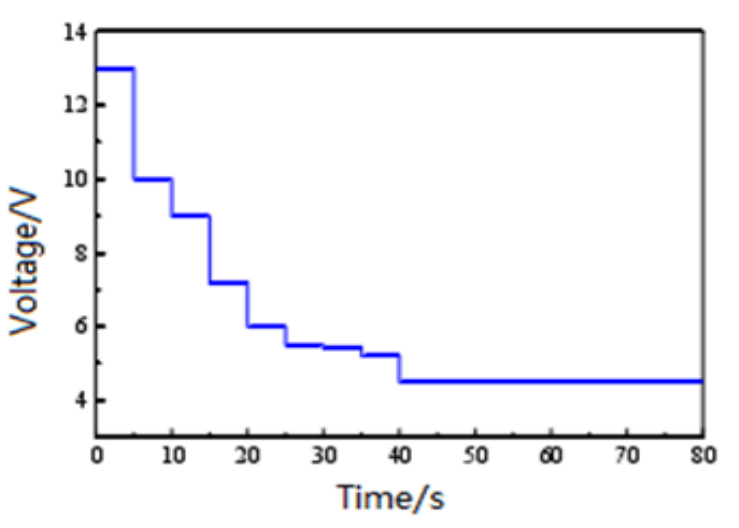

Figure 5: The step voltage to be applied on the model of the sensor

Fig. 6 is the temperature distribution at different electrolyte layer. The different grays in the figure represent the different temperatures. The gray from shallow to deep shows the temperature changing from small too big. The right side of each small figure shows the different temperature range area, Fig. 7 is the response curve of each layer of the highest temperature point.

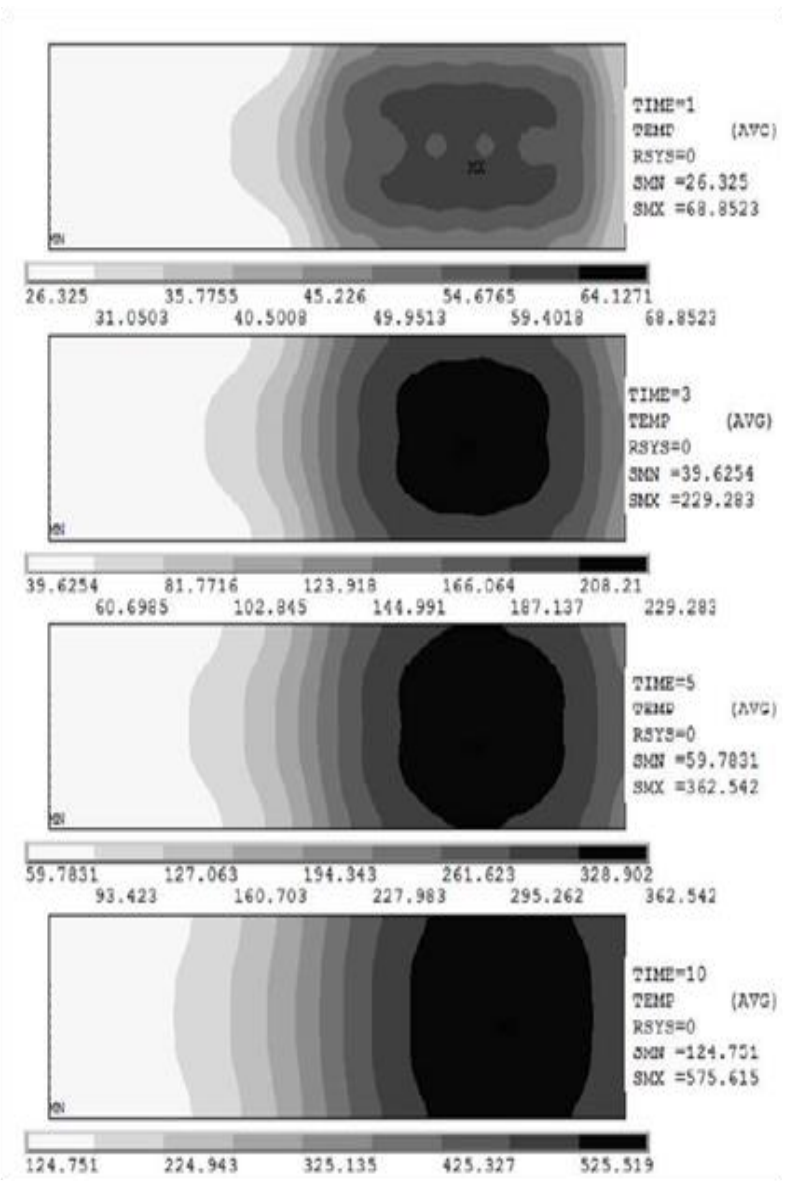

Figure 6: The temperature distribution of zirconia plate when $t=l s, 3 s, 5 s, 10 s, 20 s$ and $43 s$

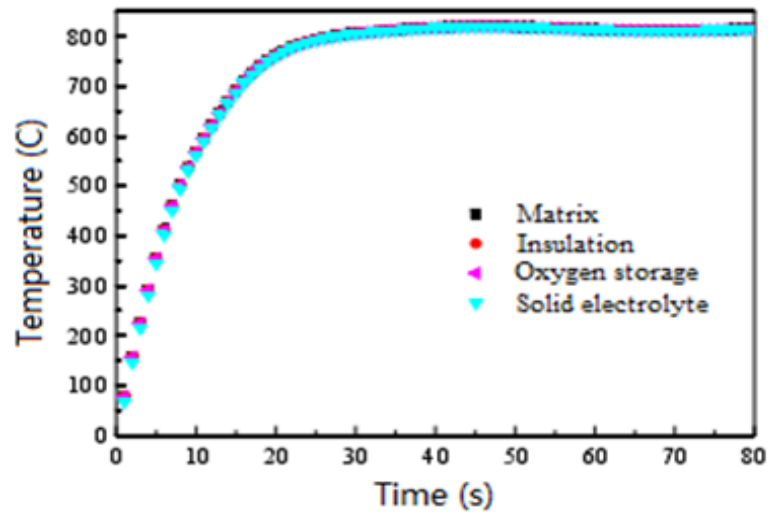

Figure 7: The temperature response diagram of each Layer of high temperature point

When $t=1 s$, the distribution of the black area is just the part of the heater winding. With the extension of time, the black area has gradually extended to the surrounding. When $t=5 s$, the front part of the plate has already reached the response temperature (above $300^{\circ} \mathrm{C}$ ). After that, the heat gradually transfers to the end of the zirconium plate, and black area gradually expanded. However, because the front of zirconium plate can be quickly heated under the action of heater layer, the rear temperature is always lower than the tip temperature. Large parts of rear end are heater wire and assembly part, and the heat continuously transfers to them. In addition, the assembly volume is greater than the volume of the zirconium plate, and the heat pass is quick. Therefore, the temperature at the back end of the plate is always low. The temperature of sensor layer rises rapidly, and the high temperature in each layer at each time point is the same. This feature shows that the sensor temperature in the thickness direction is consistent, which is very important for the stability of sensor output signal. When $\mathrm{t}=43 \mathrm{~s}$, the temperature of each layer of the sensor is basically stable, and the temperature distribution of each layer is shown in Fig. 8 and Fig. 9.

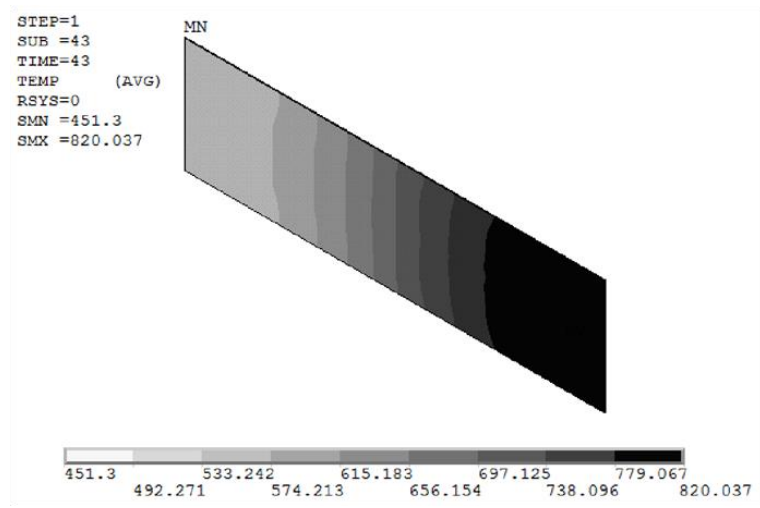

Figure 8: The temperature distribution of basal body layer after sensor stability 


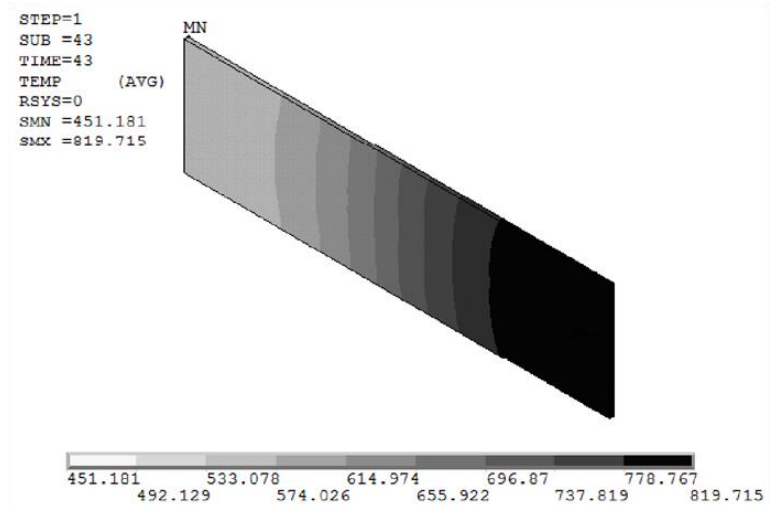

Figure 9: The temperature distribution of insulating layer after sensor stability

\subsection{Thermal coupling analysis}

In practical applications, the sensor will be affected by the thermal stress and the mechanical stress produced by the assembly. This chapter only simulates the thermal efficiency of the sensor.

A method of using indirect thermal stress analysis, thermal analysis unit (SOLID69) is converted into a corresponding structure analysis unit (SOLID45), as the hot temperature load analysis into the thermal analysis of the temperature data, are applied to each node to solve. Thermal stress is assumed to be $25{ }^{\circ} \mathrm{C}$ at room temperature. The relationship between the equivalent stress and the time of each layer of the sensor is obtained by the thermal hazard analysis, as shown in Fig. 10.

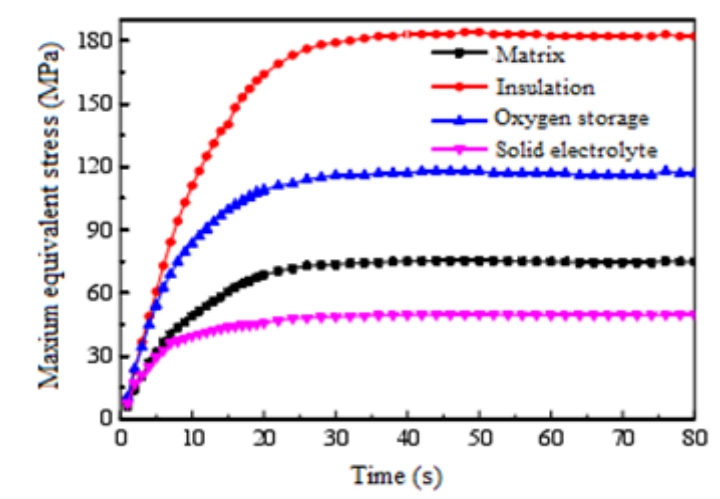

Figure 10: The maximum von mises curve of each layer

From the Fig. 10 we can see that:

(1) The maximum equivalent stress of the sensor in the first 30s increases rapidly and then tends to be stable, which is similar to the temperature rise. This is because as the temperature increases, the average stress inside the sensor increases. At the same time, when the temperature field is stable, then the thermal stress of the sensor is also stabilized.
(2) Al203 insulation layer and solid-state oxygen storage layer of the equivalent stress is large, which should be close to the heater insulation. The temperature gradient is relatively large, so the equivalent stress value is large. Because $\mathrm{CZ}$ oxygen storage material thermal expansion coefficient is large, the equivalent stress value of solid-state oxygen storage layer is relatively large.

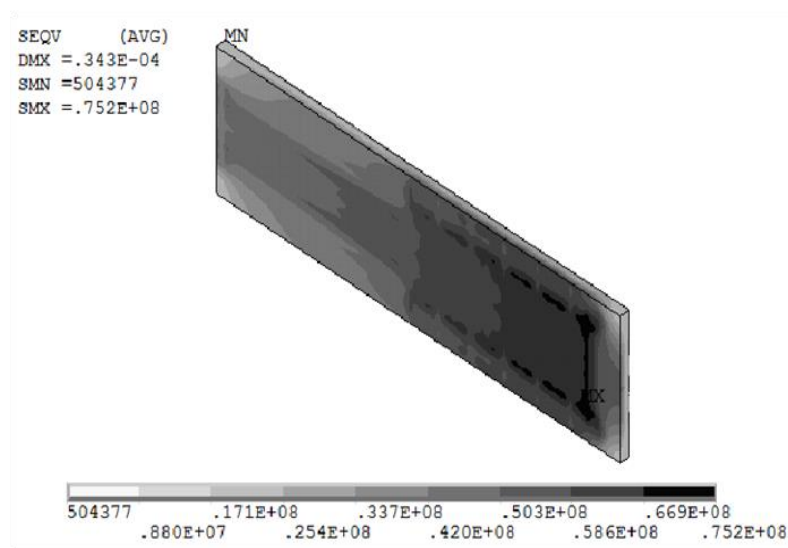

Figure 11: The stress distribution of basal body layer after $8 Y S Z$ sensor stability

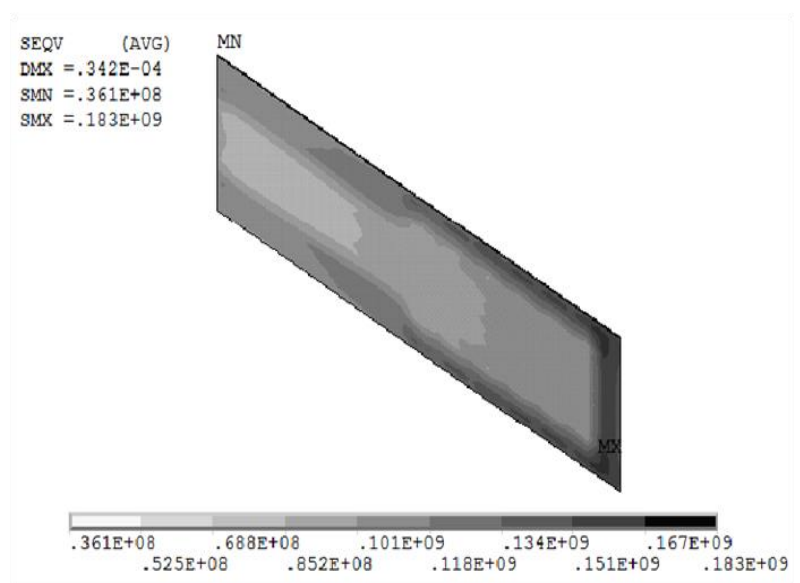

Figure 12: The stress distribution of insulating layer after 8YSZ sensor stability

The maximum equivalent stress of each layer tends to be stable at $\mathrm{t}=43 \mathrm{~s}$, which is consistent with the temperature variation of the sensor.After stable, the maximum equivalent stress of the base layer and the insulating layer are $75.2 \mathrm{MPa}$ and $183 \mathrm{MPa}$, respectively. The stress distributions are shown in Fig. 11 and Fig.12.The maximum thermal stress at each layer is outside the outer edge of the material in the heater distribution area.At this point, the fracture strength of Al203, CZ and YSZ are 249MPa, $195 \mathrm{MPa}$ and $240 \mathrm{MPa}$, respectively. The thermal stress of each layer is smaller than the fracture strength of each material itself, and it meets the requirements. 


\section{Conclusion}

In this paper, the temperature field and the thermal stress field of the plate type differential oxygen sensor are simulated and analyzed.

The results show that: When $t=5 \mathrm{~s}$, the sensor sensitive area temperature has reached the response temperature above $3000^{\circ} \mathrm{C}$. When $\mathrm{t}=43 \mathrm{~s}$, the temperature of each layer of the sensor tends to be stable. At this time, the sensitive area temperature is about $800^{\circ} \mathrm{C}$. Sensor stability is used 8YSZ as solid electrolyte, and the maximum thermal stress of each layer of Al203, CZ, 8YSZ are $183 \mathrm{MPa}, 118 \mathrm{MPa}$, and 49.6MPa. When the electrolyte material is replaced by 3YSZ, the maximum thermal stress of each layer of Al203, CZ and 8YSZ are 204MPa, $165 \mathrm{MPa}, 6 \mathrm{MPa}$ 87. 8YSZ is used as the maximum thermal stress of the solid electrolyte oxygen sensor, which is less than the maximum thermal stress under the corresponding condition of 3YSZ sensor.

The maximum thermal stress of two layers of solid electrolyte sensor under steady state is less than the fracture strength of material.

\section{Reference}

[1] Ab Kadir, R., Li, Z., Sadek, A.Z., Abdul Rani, R., Zoolfakar, A. S., Field, M. R. \& Kalantar-Zadeh, K. (2014). Electrospun granular hollow SnO2 nanofibers hydrogen gas sensors operating at low temperatures. The Journal of Physical Chemistry C, 118(6), 3129-3139.

[2] Arndt, C. M., Papageorge, M. J., Fuest, F., Sutton, J. A., Meier, W., \& Aigner, M. (2016). The role of temperature, mixture fraction, and scalar dissipation rate on transient methane injection and auto-ignition in a jet in hot coflow burner. Combustion and Flame, 167, 60-71.

[3] Bektas, M., Schönauer-Kamin, D., Hagen, G., Mergner, A., Bojer, C., Lippert, S., ... \& Moos, R. (2014). BaFe 1-x Ta x 0 3- $\delta-A$ material for temperature independent resistive oxygen sensors. Sensors and Actuators B: Chemical, 190, 208-213.

[4] Chan, N. Y., Zhao, M., Huang, J., Au, K., Wong, M. H., Yao, H. M., ... \& Dai, J. (2014). Highly sensitive gas sensor by the LaAlO3/SrTiO3 heterostructure with Pd nanoparticle surface modulation. Advanced Materials, 26(34), 5962-5968.

[5] Chen, J., Zhang, J., Wang, M., \& Li, Y. (2014). Hightemperature hydrogen sensor based on platinum nanoparticle-decorated $\mathrm{SiC}$ nanowire device. Sensors and Actuators B: Chemical, 201, 402-406.

[6] Choi, K., Nam, S., Lee, Y., Lee, M., Jang, J., Kim, S. J., ... \& Cho, S. M. (2015). Reduced water vapor transmission rate of graphene gas barrier films for flexible organic field-effect transistors. ACS nano, 9(6), 5818-5824.

[7] Drmosh, Q. A., \& Yamani, Z. H. (2016). Synthesis, characterization, and hydrogen gas sensing properties of AuNs-catalyzed $\mathrm{ZnO}$ sputtered thin films. Applied Surface Science, 375, 57-64.

[8] Fraga, M. A., Furlan, H., Pessoa, R. S., \& Massi, M. (2014). Wide bandgap semiconductor thin films for piezoelectric and piezoresistive MEMS sensors applied at high temperatures: an overview. Microsystem technologies, 20(1), 921.

[9] Gardon, M., \& Guilemany, J. M. (2013). A review on fabrication, sensing mechanisms and performance of metal oxide gas sensors. Journal of Materials Science: Materials in Electronics, 24(5), 1410-1421.

[10] Hübert, T., Boon-Brett, L., Palmisano, V., \& Bader, M. A. (2014). Developments in gas sensor technology for hydrogen safety. international Journal of hydrogen energy, 39(35), 20474-20483.

[11] Hosseini, Z. S., \& Mortezaali, A. (2015). Room temperature $\mathrm{H} 2 \mathrm{~S}$ gas sensor based on rather aligned ZnO nanorods with flower-like structures. Sensors and Actuators B: Chemical, 207, 865-871.

[12] Hu, N., Yang, Z., Wang, Y., Zhang, L., Wang, Y., Huang, X., ... \& Zhang, Y. (2013). Ultrafast and sensitive room temperature NH3 gas sensors based on chemically reduced graphene oxide. Nanotechnology, 25(2), 025502.

[13] Helwig, N., Schüler, M., Bur, C., Schütze, A., \& Sauerwald, T. (2014). Gas mixing apparatus for automated gas sensor characterization. Measurement Science and Technology, 25(5), 055903.

[14] Halfaya, Y., Bishop, C., Soltani, A., Sundaram, S., Aubry, V., Voss, P. L., ... \& Ougazzaden, A. (2016). Investigation of the performance of HEMTbased NO, NO2 and NH3 exhaust gas sensors for automotive antipollution systems. Sensors, 16(3), 273.

[15] Houidi, M. B., Sotton, J., \& Bellenoue, M. (2016). Interpretation of auto-ignition delays from RCM in the presence of temperature heterogeneities: Impact on combustion regimes and negative temperature coefficient behavior. Fuel, 186, 476-495.

[16] Ikeda, H., Iio, A., Anggraini, S. A., \& Miura, N. (2017). Impedancemetric YSZ-based oxygen sensor using $\mathrm{BaFeO} \quad 3$ sensing-electrode. Sensors and Actuators B: Chemical, 243, 279282.

[17] Jang, B., Kim, W., Song, M. J., \& Lee, W. (2017). Thermal stability of the sensing properties in $\mathrm{H}$ 2 sensors composed of Pd nanogaps on an Elastomeric Substrate. Sensors and Actuators B: Chemical, 240, 186-192. 
[18] Kita, J., Engelbrecht, A., Schubert, F., Groß, A., Rettig, F., \& Moos, R. (2015). Some practical points to consider with respect to thermal conductivity and electrical resistivity of ceramic substrates for high-temperature gas sensors. Sensors and Actuators B: Chemical, 213, 541546.

[19] Li, B., Yassine, O., \& Kosel, J. (2015). A surface acoustic wave passive and wireless sensor for magnetic fields, temperature, and humidity. IEEE Sensors Journal, 15(1), 453-462.

[20] Maier, K., Helwig, A., Müller, G., Becker, P., Hille, P., Schörmann, J., ... \& Eickhoff, M. (2014). Detection of oxidising gases using an optochemical sensor system based on GaN/InGaN nanowires. Sensors and Actuators B: Chemical, 197, 87-94.

[21] Qin, Y., Fan, G., Liu, K., \& Hu, M. (2014). Vanadium pentoxide hierarchical structure networks for high performance ethanol gas sensor with dual working temperature characteristic. Sensors and Actuators B: Chemical, 190, 141-148.

[22] Ryu, G. S., Park, K. H., Park, W. T., Kim, Y. H., \& Noh, Y. Y. (2015). High-performance diketopyrrolopyrrole-based organic field-effect transistors for flexible gas sensors. Organic Electronics, 23, 76-81.

[23] Rao, P., Godbole, R. V., \& Bhagwat, S. (2016). Copper doped nickel ferrite nano-crystalline thin films: A potential gas sensor towards reducing gases. Materials Chemistry and Physics, 171, 260-266.
[24] Thirumalairajan, S., Girija, K., Mastelaro, V. R., \& Ponpandian, N. (2014). Surface morphologydependent room-temperature LaFeO3 nanostructure thin films as selective NO2 gas sensor prepared by radio frequency magnetron sputtering. ACS applied materials \& interfaces, 6(16), 13917-13927.

[25] Wang, J., Yang, P., \& Wei, X. (2015). Highperformance, room-temperature, and nohumidity-impact ammonia sensor based on heterogeneous nickel oxide and zinc oxide nanocrystals. ACS applied materials \& interfaces, 7(6), 3816-3824.

[26] Wales, D. J., Grand, J., Ting, V. P., Burke, R. D., Edler, K. J., Bowen, C. R., ... \& Burrows, A. D. (2015). Gas sensing using porous materials for automotive applications. Chemical Society Reviews, 44(13), 4290-4321.

[27] Xiong, Y., Xue, Q., Ling, C., Lu, W., Ding, D., Zhu, L., \& Li, X. (2017). Effective CO 2 detection based on LaOCl-doped SnO 2 nanofibers: Insight into the role of oxygen in carrier gas. Sensors and Actuators B: Chemical, 241, 725-734.

[28] Yadav, A. A., Lokhande, A. C., Shinde, P. A., Kim, J. H., \& Lokhande, C. D. (2017). CO2 gas sensing properties of La203 thin films deposited at various substrate temperatures. Journal of Materials Science: Materials in Electronics, 1-8.

[29] Yang, Q., Cui, X., Liu, J., Zhao, J., Wang, Y., Gao, Y., ... \& Lu, G. (2016). A low temperature operating gas sensor with high response to NO 2 based on ordered mesoporous Ni-doped in 203 . New Journal of Chemistry, 40(3), 2376-2382.

[30] Zhao, C. X., Li, Y. F., Zhou, J., Li, L. Y., Deng, S. Z., $\mathrm{Xu}$, N. S., \& Chen, J. (2013). Large-scale synthesis of bicrystalline $\mathrm{ZnO}$ nanowire arrays by thermal oxidation of zinc film: growth mechanism and high-performance field emission. Crystal Growth \& Design, 13(7), 2897-2905. 